\title{
WIRTSCHAFT UND RECHT NACH
}

\author{
DER MATERIALISTISCHEN \\ GESCHICHTSAUFFASSUNG
}

EINE SOZIALPHILOSOPHISCHE UNTERSUCHUNG

$$
\text { VON }
$$

$D^{R}$ RUDOLF STAMMLER

PROFESSOR AN DER UNIVERSITÄT HALLE A. S.

Vitam impendere vero

ZWEITE VERBESSERTE AUFLAGE

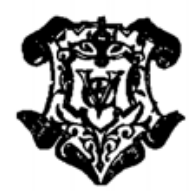

LEIPZIG

VERLAG VON VEIT \& COMP.

1906 
Druck von Metzger \& Wittig in Leipzig. 
MEINEM LIEBEN FREUNDE

\section{PAUL NATORP}

ZUGEEIGNET 
